\section{Gastric rupture before puncture of the stomach in percutaneous gastrostomy}

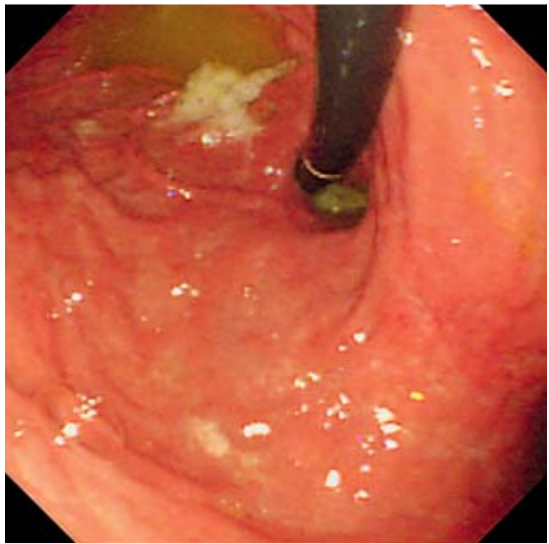

Fig. 1 No gross abnormalities were found when a flexible endoscope was inserted into the stomach.

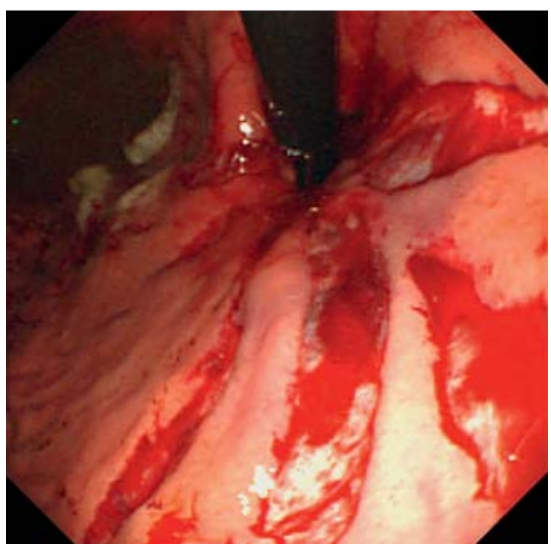

Fig. 2 During gastric insufflations, performed before puncture of the stomach for a percutaneous endoscopic gastrostomy (PEG), several fusiform-shaped tears developed along the lesser curvature of the proximal stomach.

A 73-year-old man had swallowing difficulties because of a recent cerebrovascular accident, and was on enteral feeding via a nasogastric tube. Percutaneous endoscopic gastrostomy (PEG) was chosen for long-term enteral feeding. Before the PEG tube was inserted, a flexible endoscope was inserted into the stomach for inspection. No gross abnormal lesion was detected in the upper gastrointestinal tract $(\bullet$ Fig. 1).

Then, before puncturing, the stomach was insufflated and indentation of the gastric lumen was confirmed by finger palpation of the abdominal wall. This caused the patient to choke a few times. Subsequently, bleeding occurred in the upper stomach. Several fusiform-shaped tears had developed along the lesser curvature of the proximal stomach ( Fig. 2 ).

Computed tomography (CT) imaging revealed pneumoperitoneum ( $\bullet$ Fig.3a) and pneumomediastinum ( $\bullet$ Fig. $\mathbf{3 b}$ ), requiring emergency laparotomy.

A 2-cm-long full-thickness tear along the lesser curvature of the stomach close to the cardia was identified and sutured.

Gastric rupture is caused by increased gastric pressure resulting from increased intra-abdominal pressure, with or without overdistention caused by food or gas. In more than $70 \%$ of the adult cases, gastric rupture occurs in the less distensible proximal lesser curvature of the stomach [1]. Spontaneous gastric rupture occurs due to vomiting, vigorous coughing, or convulsion. Its cause may also be iatrogenic, resulting from cardiopulmonary resuscitation, inadvertent esophageal intubation, Heimlich maneuver, or esophagogastroduodenoscopy (EGD) [1 -3].

Diagnostic EGD is extremely safe, and perforation of the gastrointestinal tract is rare with an incidence of $0.001 \%-0.05 \%$ [4]. Gastric rupture during gastric insuf-
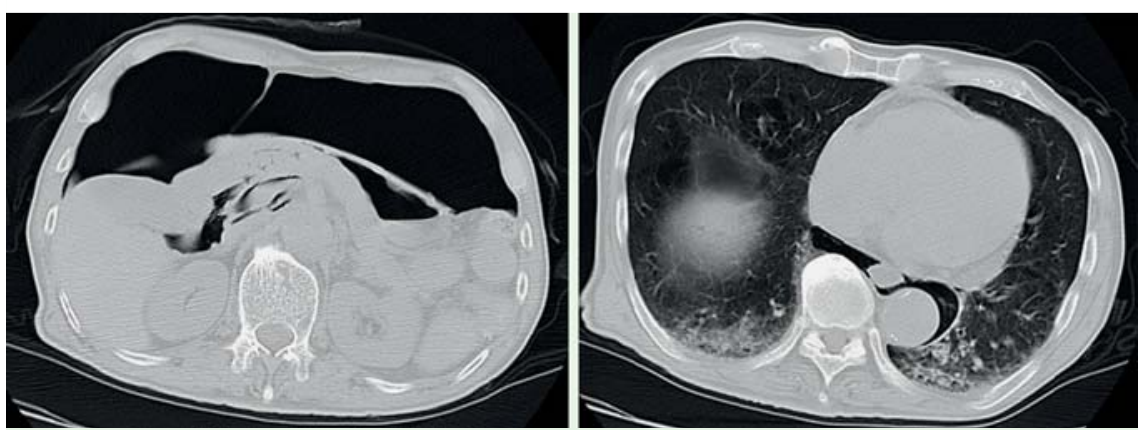

Fig. 3 Computed tomography (CT) imaging revealed a massive pneumoperitoneum and $\mathbf{b}$ pneumomediastinum. flations, which are performed before puncturing the stomach for a PEG, is also rarely reported [5]. Endoscopic gastric insufflation with air is important to avoid colon injury. In the present case, the patient's choking during gastric insufflations, which led to a sudden increase in intra-abdominal pressure, may have caused the gastric rupture. Endoscopists should consider this rare yet potentially lethal complication.

\section{Endoscopy_UCTN_Code_CPL_1AH_2AI}

\section{Competing interests: None}

Y. Matsunaga ${ }^{1}$, A. Goto ${ }^{1}$, H. Kaneko ${ }^{2}$,

N. Hasegawa ${ }^{2}$, H. Wakasugi ${ }^{1}$, M. Itoh ${ }^{1}$,

K. Fujii ${ }^{1}$, K. Suzuki ${ }^{1}$, K. Nakahata ${ }^{1}$,

Y. Shinomura ${ }^{3}$

Department of Gastroenterology, Kushiro City General Hospital, Kushiro, Japan

2 Department of Surgery, Kushiro City General Hospital, Kushiro, Japan

3 First Department of Internal Medicine, Sapporo Medical University, Sapporo, Japan

\section{References}

1 Barker SJ, Karagianes T. Gastric barotrauma: a case report and theoretical considerations. Anesth Analg 1985; 64: 1026 - 1028

2 Tung PH, Law S, Chu KM et al. Gastric rupture after Heimlich maneuver and cardiopulmonary resuscitation. Hepatogastroenterology 2001; 48: 109-111

3 Ho CM, Yin IW, Tsou KF et al. Gastric rupture after awake fibreoptic intubation in a patient with laryngeal carcinoma. $\mathrm{Br} \mathrm{J}$ Anaesth 2005; 94: 856-858

4 Misra T, Lalor E, Fedorak RN. Endoscopic perforation rates at a Canadian university teaching hospital. Can J Gastroenterol 2004; 18: $221-226$

5 Schrag SP, Sharma R, Jaik NP et al. Complications related to percutaneous endoscopic gastrostomy (PEG) tubes. A comprehensive clinical review. J Gastrointestin Liver Dis 2007; 16: 407-418

Bibliography

DOI $10.1055 / \mathrm{s}-0030-1256077$

Endoscopy 2011; 43: E57

(c) Georg Thieme Verlag KG Stuttgart · New York . ISSN 0013-726X

\section{Corresponding author}

\section{A. Goto, MD, PhD}

Department of Gastroenterology

Kushiro City General Hospital

1-12, Shunkodai

Kushiro, 085-0822

Japan

Fax: +81-0154-414080

goa@sapmed.ac.jp 